\title{
Macroalgas bentônicas associadas a bancos de Hypnea musciformis (Wulfen) J.V. Lamour. (Rhodophyta - Gigartinales) em duas praias do litoral baiano
}

Iara Oliveira Costa ${ }^{1,4}$, Taiara Aguiar Caires ${ }^{1}$, Guilherme Henrique Pereira Filho ${ }^{2}$ e José Marcos de Castro Nunes ${ }^{1,3}$

Recebido em 21/06/2011. Aceito em 20/02/2012

\section{RESUMO}

(Macroalgas bentônicas associadas a bancos de Hypnea musciformis (Rhodophyta-Gigartinales) em duas praias do litoral baiano). Este trabalho caracteriza a estrutura e dinâmica das comunidades de macroalgas bentônicas associadas a populações de H. musciformis ocorrentes em formações recifais nas praias de Stella Maris (Salvador) e Itacimirim (Camaçari). As coletas ocorreram entre agosto de 2007 e junho de 2008. As formações recifais foram divididas em compartimentos com base no hidrodinamismo. Utilizou-se três transectos em cada compartimento, onde foram dispostos cinco quadrados de 20 x $20 \mathrm{~cm}$. Foram obtidos dados de riqueza, biomassa, percentual de importância (Pi\%), diversidade (H') e equitabilidade (J'). Na área estudada ocorreram 60 espécies: 30 Rhodophyta, 20 Chlorophyta e 10 Ochrophyta; biomassa média de 136 g.m² (peso seco); e índices médios de H’ e J’ de 2,7 e 0,97, respectivamente. Houve predominância das rodofíceas, tanto em riqueza específica quanto em valores de biomassa. Foi encontrada maior contribuição do grupo morfo-funcional de algas corticadas. Dentre a flora associada, Gelidiella acerosa, Sargassum cymosum e Palisada perforata apresentaram maiores valores de biomassa. O compartimento recifal mais representativo em riqueza específica e biomassa foi a região frontal do recife. As comunidades das praias estudadas foram consideradas distintas devido à fisionomia das formações recifais.

Palavras-chave: Bahia. Ecologia de macroalgas. Estrutura de comunidades. Flora associada. Mediolitoral

\begin{abstract}
(Macroalgae associated with banks of Hypnea musciformis (Wulfen) J.V. Lamour. (Rhodophyta, Gigartinales) on two beaches on the coast of Bahia). This study characterized the structure and dynamics of macroalgae communities associated with benthic populations of $H$. musciformis occurring in reef formations on the beaches of Stella Maris (Salvador) and Itacimirim (Camaçari), Bahia. The samples were collected between August 2007 and June 2008. The reef formations were divided into compartments based on hydrodynamics. Three transects where made for each compartment, and each of these had five quadrants of $20 \mathrm{x} 20 \mathrm{~cm}$. Data about the richness, biomass, percentage of importance (Pi\%), diversity (H') and evenness (J') was collected. The study recorded 60 species, 30 Rhodophyta, 20 Chlorophyta and 10 Ochrophyta, which had an average biomass of $136 \mathrm{~g} \cdot \mathrm{m}^{-2}$ (dry weight) and average rates of H' and J' of 2.7 and 0.97 , respectively. There was a predominance of red algae, both in values of richness and in biomass. The contribution of the morpho-functional group of the cortical algae was greater. Among the flora recorded, Gelidiella acerosa, Sargassum cymosum and Palisada perforata had higher biomasses. The reef compartment with the highest species richness and biomass was the frontal region. The communities of the beaches studied were considered distinct because of the physiognomy of the reef formations.
\end{abstract}

Key words: Bahia. Ecology of macroalgae. Community structure. Flora associated. Midlittoral

1 Universidade Federal da Bahia, Instituto de Biologia, Departamento de Botânica, Laboratório de Algas Marinhas, Salvador, BA, Brasil

2 Universidade Federal Rural do Rio de Janeiro, Departamento de Botânica, Seropédica, RJ, Brasil

3 Universidade do Estado da Bahia, Departamento de Ciências Exatas e da Terra, Campus II, Alagoinhas, BA, Brasil

4 Autor para correspondência: iaraoc@hotmail.com 


\section{Introdução}

As macroalgas são comuns ao longo de toda costa brasileira sendo, entretanto, mais abundantes e diversificadas em áreas com substratos rochosos e águas mais transparentes, como é o caso da costa nordeste do país, onde ocorre menor aporte de sedimentos e água doce devido à ausência de grandes rios (Oliveira 2002). O trecho do litoral nordeste, localizado entre as costas do Ceará e da Bahia, é caracterizado por possuir águas oligotróficas e abundância de substratos rochosos, propícios ao crescimento de uma flora com marcada diversidade de espécies, estando incluídas entre as mais representativas do País (Horta et al. 2001; Pereira 2002). A flora marinha do litoral baiano encontra-se estabelecida predominantemente sobre recifes de arenito incrustados por algas calcárias e corais (Nunes 2005a). As rodofíceas calcárias não articuladas funcionam como construtoras da formação recifal juntamente com os corais, formando uma estrutura tridimensional que, além de, possuir elevada capacidade de reciclar nutrientes, serve como local para o estabelecimento de uma infinidade de organismos de diferentes categorias, principalmente na época reprodutiva (Villaça 2002). Apesar das comunidades algáceas apresentarem considerável diversidade de espécies, o conhecimento sobre a sua estrutura ainda é escasso, o que dificulta uma maior compreensão sobre esse ecossistema (Pereira 2002).

Os recifes bióticos do litoral baiano constituem as maiores e mais ricas estruturas recifais de toda a costa brasileira, bem como, de todo Atlântico Sul Ocidental, sendo que a área de maior incidência é a região de Abrolhos, no litoral sul do Estado (Laborel 1967). As algas são responsáveis por grande parte da produção primária nos recifes, sendo estas formações tipicamente tropicais com grande riqueza de espécies e microhabitats (Lobban \& Harrison 1994; Muñoz \& Pereira 1997).

Dentre os táxons da divisão Rhodophyta o gênero Hypnea (Gigartinales) tem sido amplamente estudado por possuir em sua parede celular kapa carragenana, substância utilizada industrialmente como agente geleificante, estabilizante, espessante ou emulsificante (Reis \& Yoneshigue-Valentin 1998). Este gênero tem ampla distribuição na costa tropical e subtropical do mundo (Bouzon 2006), sendo Hypnea musciformis (Wulfen) J.V. Lamour. a espécie mais abundante do gênero, com ocorrência nos Oceanos Atlântico, Índico e Pacífico (Oliveira 1977) e com ampla distribuição ao longo do litoral brasileiro, ocorrendo desde o Maranhão até o Rio grande do Sul, incluindo as ilhas oceânicas (Nunes 2005a). No estudo realizado por Reis \& Yoneshigue-Valentin (1998), esta espécie foi encontrada formando densos bancos e emaranhada com outras algas, no litoral do Rio de Janeiro, a exemplo de várias espécies do gênero Sargassum, utilizando-as como importante substrato para seu desenvolvimento. Por apresentar grande interesse econômico $H$. musciformis, vem sofrendo com a coleta indiscriminada para fins comerciais, principalmente na região nordeste do Brasil (Pereira 2002).

Apesar de o litoral baiano ser uma região que apresenta grande diversidade de substratos e acidentes geográficos, o que se reflete em uma diversificação da flora marinha (Nunes 2005a), nas últimas décadas esta zona costeira vem passando por um intenso processo de desenvolvimento urbano, o que tem provocado pressões e impactos ambientais significativos em várias regiões.

Como as macroalgas contribuem largamente para o funcionamento dos ecossistemas costeiros, sobretudo na oxigenação do meio, absorção e transformação de nutrientes inorgânicos e na sustentação da cadeia alimentar, Steneck \& Dethier (1994), sugerem o uso de grupos morfo-funcionais de algas marinhas, caracterizados pela semelhança entre espécies que tem as mesmas características morfológicas e anatômicas críticas em estudos que descrevem a estrutura das comunidades bentônicas. Desse modo, os grupamentos de macroalgas podem ser divididos em sete categorias: microalgas, algas filamentosas, algas foliáceas, algas cilíndrico-corticadas, algas coriáceas, algas calcáreas articuladas e algas incrustantes. Como os padrões morfológicos muitas vezes correspondem às características ecológicas é possível predizer a composição da comunidade e os prováveis níveis de distúrbios no meio ambiente (Barbosa et al. 2008).

Vários estudos taxonômicos vêm sendo realizados no litoral da Bahia, sendo a sua flora relativamente bem conhecida, dentre esses trabalhos podemos citar: Nunes (1999), Nunes \& Paula (2000, 2001, 2002, 2004a, 2004b, 2006), Barreto et al. (2004), Nunes et al. (2004), Nunes (2005a, 2005b), Lyra et al. (2007), Marins et al. (2008), Alves (2008), Nunes \& Guimarães $(2009,2010)$ e Bahia et al. (2010).

Estudos relacionados à caracterização de comunidades de macroalgas marinhas são recentes no litoral brasileiro, a maioria trata da caracterização de comunidades algáceas do infralitoral, com bancos de rodolitos (Amado-Filho et al. 2007, 2010; Riul et al. 2009; Bahia et al. 2010) e formações recifais (Villaça \& Pitombo 1997; Costa Jr. et al. 2002; Amado-Filho et al. 2003, 2006, 2007, 2010; Figueiredo et al. 2004; Oigman-Pszczol et al. 2004; Horta et al. 2008; Marins et al. 2008; Ribeiro et al. 2008; Villaça et al. 2008; Reis 2009; Cocentino et al. 2010). Dentre os estudos que enfocam estruturas de comunidades de macroalgas do litoral brasileiro no mediolitoral destacam-se Muñoz \& Pereira (1997), Oliveira-Carvalho et al. (2003), Barbosa et al. (2008) e Villaça et al. (2010). Os trabalhos sobre a estrutura de comunidades das macroalgas marinhas do mediolitoral baiano são inexistentes.

Em função da crescente expansão imobiliária e industrial ocorrente na Região Metropolitana de Salvador, diversos impactos têm afetado os ambientes costeiros e, por conseguinte, podem se refletir sobre os bancos de macroalgas como os formados por Hypnea musciformis e sua abundante flora associada. Assim, faz-se necessário a realização de estudos que caracterizem esses ambientes, visando 
gerar subsídios para futuros programas de monitoramento. Neste contexto, este trabalho tem por objetivo caracterizar a estrutura e dinâmica das comunidades de macroalgas bentônicas associadas a populações de $H$. musciformis ocorrentes em formações recifais nas praias de Stella Maris (Salvador) e Itacimirim (Camaçari) do estado da Bahia.

\section{Material e métodos}

A praia de Stella Maris localiza-se na cidade de Salvador $\left(12^{\circ} 56^{\prime} 22,92^{\prime \prime} \mathrm{S}\right.$ x $\left.38^{\circ} 19^{\prime} 41,22^{\prime \prime} \mathrm{W}\right)$, possui estrutura recifal formada por recifes corais-algais superficiais e crostas calcárias de composição orgânica (algas vermelhas incrustantes associadas, na maioria das vezes, às incrustações de gastrópodes vermetídeos) que ocorrem sobre rochas de praia. A praia de Itacimirim está localizada no município de Camaçari $\left(12^{\circ} 36^{\prime} 53,82^{\prime \prime} \mathrm{S}\right.$ x $\left.38^{\circ} 02^{\prime} 31,87^{\prime \prime} \mathrm{W}\right)$ e apresenta uma construção carbonática rochosa, cujos construtores são os corais e algas coralinas incrustantes. As construções carbonáticas das praias de Stella Maris e Itacimirim apresentam morfologia semelhante, com uma superfície irregular devido à presença de poças com formas e tamanhos variados, bem como regiões mais altas e rochosas cobertas por algas moles e/ou calcárias (Nolasco 1988).

Foram realizadas quatro coletas durante o período de agosto de 2007 a junho de 2008, sendo duas no período chuvoso (junho e agosto) e duas no seco (fevereiro e novembro). As amostragens foram realizadas durante as marés baixas de sizígia, na região do mediolitoral.

As formações recifais foram divididas em três microhabitats segundo Nunes \& Paula (2002). Assim sendo, para a praia de Stella Maris foram determinados três compartimentos: região frontal do recife (RFR), região protegida do recife (RPR) e poças de maré (PÇ). O recife da praia de Itacimirim, devido à sua diferente morfologia, foi dividido em região frontal do recife (RFR), platô recifal (PR) e poças de maré (PÇ). Foram utilizados três transectos de $20 \mathrm{~m}$ de extensão cada, para cada compartimento recifal, posicionados paralelamente à linha de arrebentação das ondas. Em cada transecto foram posicionados aleatoriamente (utilizando-se uma tabela de números aleatórios) cinco quadrados de $20 \times 20 \mathrm{~cm}$. Para as amostragens todos os exemplares contidos nos quadrados foram retirados com auxílio de espátulas e preservados de acordo com Nunes (2010). Amostragens qualitativas também foram realizadas. A exemplo do que foi adotado por Marins et al. (2008) não foram consideradas as algas calcárias incrustantes, pois essas apresentam taxonomia complexa e, no Brasil, este grupo ainda não recebeu um tratamento taxonômico abrangente.

No laboratório foi realizada a identificação taxonômica através de chaves e descrições disponíveis em levantamentos florísticos, dissertações, teses e trabalhos específicos. Para o posicionamento taxonômico das espécies utilizou-se Wynne (2011).
Para a determinação da biomassa as algas foram secas em estufa à $60^{\circ} \mathrm{C}$ até se obter peso constante. A biomassa seca de cada espécie foi registrada através de balança semi-analítica $(0,001)$. Todo o material estudado encontra-se registrado e depositado no Herbário Alexandre Leal Costa (ALCB) do Instituto de Biologia da Universidade Federal da Bahia.

Os resultados de cada ponto e época (chuvosa e seca) de coleta foram comparados quanto ao número total de táxons, biomassa seca, diversidade de Shannon-Wiener $\left(\mathrm{H}^{\prime}\right)$, através a fórmula, $\mathrm{H}^{\prime}=\Sigma$ (pi.lnpi), onde $p$ é a proporção da biomassa de uma dada espécie e ln o seu logaritmo neperiano. O percentual de importância $(\mathrm{Pi})$ de cada táxon foi determinado através da fórmula: $\mathrm{Pi}=$ (biomassa média de cada táxon $\left(\mathrm{g} / \mathrm{m}^{2}\right) /$ biomassa média total $\left.\left(\mathrm{g} / \mathrm{m}^{2}\right) \times 100\right)$ (Amado Filho et al. 2003). A equitabilidade de Pielou (J) foi calculada pela fórmula $\mathrm{J}=\mathrm{H}^{\prime}$ / $\operatorname{lnS}$, onde $\mathrm{S}$ é a riqueza de espécies e $\mathrm{H}^{\prime} \mathrm{o}$ índice de diversidade. Após a verificação da homogeneidade de variâncias (Teste de Cochran) e a normalidade dos dados, foi aplicada a Análise de Variância (ANOVA) unifatorial ou bifatorial para testar diferenças entre os tratamentos, seguida pelo teste de Tukey quando necessário $(p<0,05)$ (Zar 1996). Através dos dados brutos de biomassa, com 180 amostras e 60 espécies, transformadas $(\log (\mathrm{x}+1))$, foi calculado o índice de similaridade de Bray-Curtis e processada a Análise de Escalonamento Multidimensional (MDS). Eventuais significâncias de diferenças observadas entre os valores de similaridades foram verificadas utilizando-se a análise ANOSIM $(\mathrm{p}<0,05)$. O grau de confiança para todos os testes de significância foi estipulado em $95 \%(p=0,05)$. Os dados de biomassa foram apresentados como média \pm desvio padrão.

\section{Resultados e discussão}

Foram identificadas um total de 60 espécies associadas às populações de Hypnea musciformis nas duas praias, sendo: $10(17 \%)$ pertencentes à divisão Ochrophyta, distribuídas em 3 ordens e 3 famílias; 20 (33\%) Chlorophyta, distribuídas em 4 ordens e 8 famílias; e 30 (50\%) Rhodophyta, distribuídas em 8 ordens e 12 famílias (Tab. 1). Para o estado da Bahia são referidas 368 espécies, sendo 54 pertencentes à divisão Ochrophyta, 77 à Chlorophyta e 237 à Rhodophyta (Fujii et al. 2008). Comparando estes valores com os valores de táxons encontrados no presente estudo, as praias estudadas apresentam aproximadamente $17 \%$ de toda a flora de macroalgas referidas para o litoral baiano.

A ordem melhor representada em número de táxons foi Ceramiales (Rhodophyta) com 13 espécies, sendo mais de $80 \%$ dos táxons pertencentes à família Rhodomelaceae. Para o estado da Bahia foram referidas 54 espécies de Rhodomelaceae, sendo a família de maior representatividade, dentre as rodofíceas (Nunes 2005a). Das espécies referidas no presente trabalho todas foram representativas em Stella Maris em ambos os períodos e compartimentos 
recifais ocorrendo com maior freqüência na RFR, onde a energia das ondas é maior, o que também foi observado em Altamirano \& Nunes (1997 - Itacimirim), Nunes (1998a - Salvador), Nunes et al. (1999 - Ilhéus), Nunes et al. (2001 Uruçuca) e Lyra et al. (2007 - Itacaré). As espécies Bryothamnion seaforthii, B. triquetrum, Enantiocladia duperreyi e Vidalia obtusiloba foram registradas somente em Stella Maris durante os períodos de coleta. Em Itacimirim foram registradas seis espécies da família Rhodomelaceae, dentre elas cinco ocorreram na RFR, corroborando com os estudos citados acima.

Dentre as Chlorophyta, a ordem Bryopsidales foi a melhor representada com 11 espécies. Resultado semelhante foi observado por Nunes (1998b - Bahia), Barata (2004 Espírito Santo) e Horta et al. (2001 - litoral sul do Brasil). O gênero Halimeda foi representado por cinco espécies, e é reconhecido por participar da construção de ambientes recifais, contribuindo com seus segmentos para a fixação de bancos de fanerógamas ou fornecendo carbonatos para o sistema recifal (Villaça 2002). O gênero Ulva foi o mais freqüente, ocorrendo em todos compartimentos recifais e em ambos os períodos (seco e chuvoso), apresentando três espécies na praia de Itacimirim (U. fasciata, U. rígida e $U$. lactuca), enquanto que em Stella Maris apenas duas destas foram encontradas (U. lactuca e U. fasciata). Barbosa et al. (2008) encontraram $U$. fasciata como táxon dominante e mais freqüente dentre as algas foliáceas, na região do mediolitoral de uma praia no Espírito Santo. Reis \& Yoneshigue-Valentin (1996) ao estudar a distribuição das macroalgas numa laguna hipersalina do Rio de Janeiro, citaram Ulva como oportunista e tolerante a amplas variações de parâmetros ambientais.

Dictyotaceae foi a família melhor representada dentre as ocrofíceas em número de espécies (oito). Resultados similares foram encontrados por Nunes \& Paula (2002) e Marins et al. (2008). Oliveira Filho (1977) comenta que essa família corresponde a $51 \%$ do total das espécies de algas pardas existentes no Brasil, sendo a mais importante quanto à biomassa na costa nordeste. Costa Jr. et al. (2002) e Marins et al. (2008) também encontraram maior contribuição de biomassa em espécies desse grupo para o infralitoral.

Para a praia de Stella Maris foram identificadas 49 espécies e Itacimirim 44. A região recifal que apresentou o maior número de táxons (31) foi a RFR da praia de Stella Maris e a que apresentou menor número (16) foi a RPR também em Stella Maris. A praia de Itacimirim apresentou valores intermediários de táxons (Fig. 2).

Do total de táxons encontrados acompanhando Hypnea musciformis sete foram comuns a todos os compartimentos recifais nas duas praias e 16 estiveram restritos apenas a uma região, destacando-se a RFR da praia de Stella Maris onde foram encontrados nove táxons exclusivos (Tab. 1). 41 táxons foram comuns aos dois períodos (chuvoso e seco). No período chuvoso ocorreu uma maior riqueza de espécies (52), sendo 12 restritas a este período. No período seco houve uma pequena redução no número de espécies (45), sendo sete limitadas a este período.

Estudos demonstram que no mediolitoral o período seco é caracterizado por apresentar maior riqueza específica, pois alguns fatores como redução da pluviosidade, menor turbidez da água e aumento da salinidade contribuem para uma maior ocorrência de espécies (Muñoz \& Pereira 1997; Oliveira-Carvalho et al. 2003; Barbosa et al. 2008). Entretanto, no presente estudo não foi observado resultado semelhante. Como os locais estudados encontram-se na faixa tropical do país, onde não existem grandes variações climáticas, uma das possíveis causas dessa pequena diferença no número de espécies entre os períodos provavelmente deve-se a pluviosidade, não sendo evidenciadas grandes variações de precipitação nos períodos de coleta (Fig. 3). Outra possível causa é que as praias estudadas têm grande atividade turística, principalmente entre os meses de setembro e fevereiro (período seco), onde o índice pluviométrico é menor, sendo assim, maior insolação durante os períodos de marés baixas. $\mathrm{O}$ aumento na atividade turística neste período dificulta a fixação e desenvolvimento das espécies, entre outros fatores, por causa do pisoteio dos recifes, situação também evidenciada no estudo realizado por Barbosa et al. (2008).

A riqueza média de espécies foi maior na praia de Stella Maris, contudo quando comparado os diferentes microhabitats entre as duas praias, a RFR variou significativamente dos demais compartimentos recifais (ANOVA, $p<0,001$ ), e esta variação provavelmente ocorreu devido ao hidrodinamismo (Fig. 4). Em estudos realizados em praias do litoral baiano por Altamirano \& Nunes (1997), Nunes et al. (1999), Nunes et al. (2001), Lucio \& Nunes (2002) e Lyra et al. (2007), constataram que o maior número de táxons foi encontrado na RFR, onde a energia das ondas é maior, e decresce com a diminuição do hidrodinamismo, sendo menor nas poças, e que por sua vez reflete na menor riqueza de espécies dentre os compartimentos recifais. Segundo Villaça et al. (2010) a RFR, apesar da constante ação das ondas, abriga riqueza relativamente alta de espécies por possuir muitas depressões e fendas. As algas que crescem nesta região estão mais tempo submersas, sofrem menos dessecação e estão menos expostas à luz solar direta do que as encontradas na região protegida do recife.

Quanto aos tipos morfo-funcionais, houve maior representatividade das algas corticadas (42\%), seguida das algas foliáceas (24\%), filamentosas (19\%), calcárias articuladas (14\%) e coriáceas (2\%) (Fig. 5). Segundo Steneck \& Dethier (1994) os grupos que possuem alargamento do córtex (corticadas e coriáceas) são mais resistentes a distúrbios físicos e biológicos, sendo favorecidas em ambientes com distúrbio moderado e de alta produtividade. A ocorrência de diversos grupos morfo-funcionais em ambas as formações recifais pode está associada à oscilação da salinidade da água (Figueiredo et al. 2004), bem como, a heterogeneidade do substrato e o diferente grau de hidrodinamismo incidente 


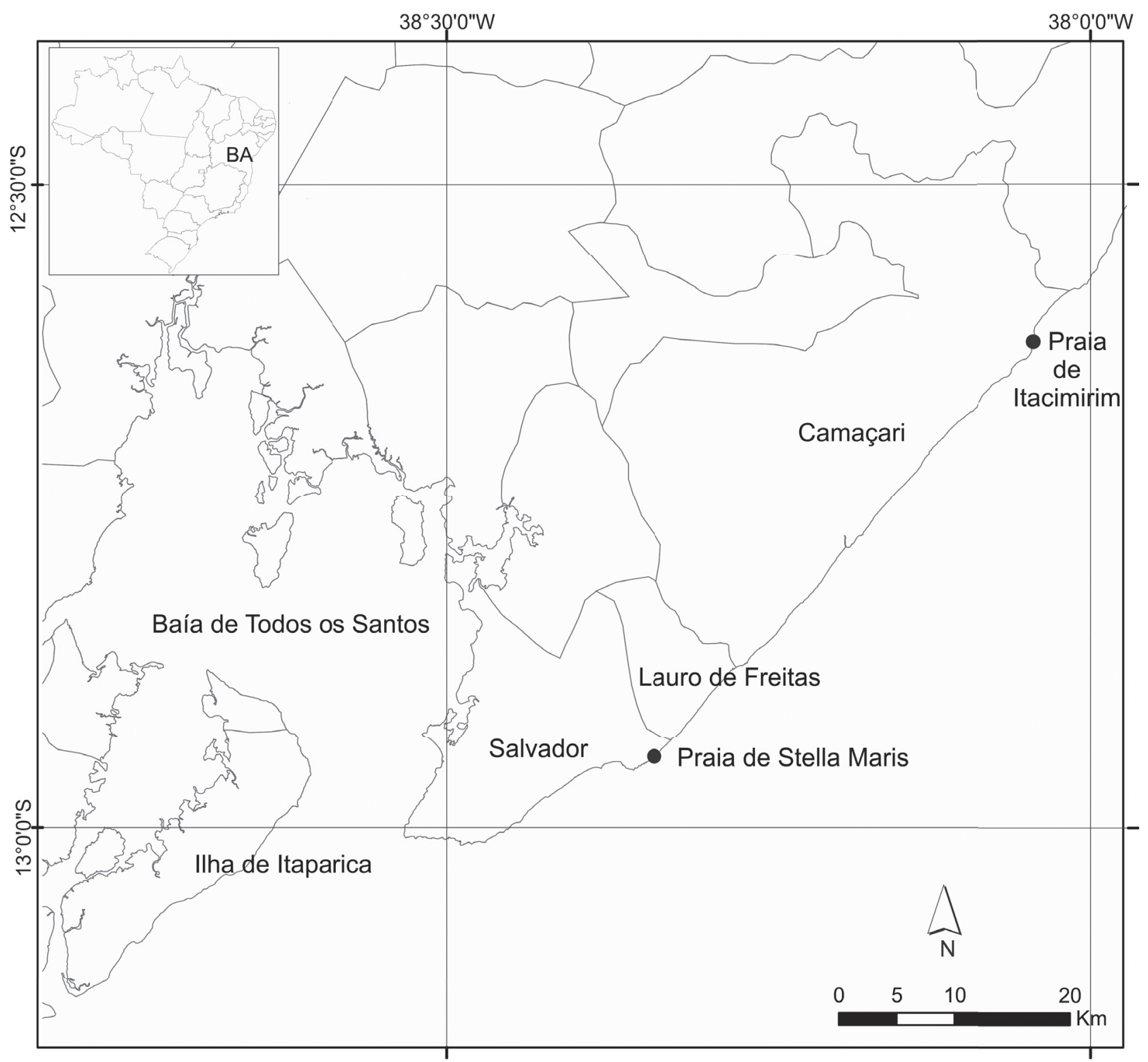

Figura 1. Mapa do estado da Bahia representando os municípios de Camaçari e Salvador.

sobre os compartimentos recifais. Indicando que, possivelmente, o ambiente das praias estudadas estaria em estado intermediário, com relação ao grau de distúrbios.

A biomassa média total, incluindo todos os pontos de coleta nos dois períodos analisados, foi de 136 g.m. ${ }^{-2}$. Quanto à biomassa média de cada uma das praias estudadas, observa-se diferença significativa $(t=3,57 ; \mathrm{p}<0,001), 162 \pm 93$ g.m $\mathrm{m}^{-2}$ em Stella Maris e $110 \pm 40$ g.m $\mathrm{m}^{-2}$ em Itacimirim. Esta diferença pode ser explicada pela heterogeneidade dos ambientes. A formação recifal de Stella Maris apresenta maior disponibilidade de substratos rochosos, e possui formação irregular, apresentando várias reentrâncias propícias ao acúmulo de sedimentos, esporos e propágulos das algas. A formação recifal de Itacimirim apresenta em sua superfície grande quantidade de substrato inconsolidado, o que dificulta o estabelecimento de alguns grupos algais. Contudo, este tipo de substrato é importante nas regiões recifais, pois possibilita à ocorrência de algas psamófitas - algas que desenvolveram adaptações para sobreviver em locais arenosos (Oliveira-Carvalho et al. 2003).

Quando comparadas as quatro coletas, foi observada diferença significativa (ANOVA, $p<0,001$ ), sendo a diferença (Tukey, $\mathrm{p}<0,001$ ) detectada entre o final do período chuvoso $\left(216 \pm 135\right.$ g.m $\left.{ }^{-2}\right)$ em Stella Maris e final do período seco $\left(68 \pm 43\right.$ g.m $\left.{ }^{-2}\right)$ em Itacimirim (Fig. 6). Essa diferença, provavelmente, se deve ao aumento de pluviosidade no início do período chuvoso (Fig. 3). Pois, os meses que antecederam a primeira coleta (agosto de 2007), não foram meses de grande precipitação, já a quarta coleta (junho de 2008) foi antecedida por meses de alta precipitação. O aumento da pluviosidade pode ter ocasionado variação de salinidade e turbidez da água, que associada à suspensão de sedimentos 
Tabela 1. Lista dos táxons encontrados e suas ocorrências nos compartimentos recifais e períodos das praias de Stella Maris e Itacimirim, indicando os respectivos morfotipos: $\mathrm{FT}=$ filamentoso; $\mathrm{F}=$ foliáceo; $\mathrm{C}=$ corticado; $\mathrm{CR}=$ coriáceo; $\mathrm{A}=$ calcária articulada; $(+)=$ presença; $(-)=$ ausência.

\begin{tabular}{|c|c|c|c|c|c|c|c|c|c|c|c|c|c|}
\hline \multirow{3}{*}{ TÁXONS } & \multicolumn{6}{|c|}{ Stella Maris } & \multicolumn{6}{|c|}{ Itacimirim } & \multirow{3}{*}{ Morfotipo } \\
\hline & \multicolumn{3}{|c|}{ Período Seco } & \multicolumn{3}{|c|}{ Período Chuvoso } & \multicolumn{3}{|c|}{ Período Seco } & \multicolumn{3}{|c|}{ Período Chuvoso } & \\
\hline & $\mathrm{PÇ}$ & RPR & RFR & $\mathrm{PÇ}$ & RPR & RFR & $\mathrm{PÇ}$ & PR & RFR & PÇ & $\mathrm{PR}$ & RFR & \\
\hline \multicolumn{14}{|l|}{ OCHROPHYTA } \\
\hline \multicolumn{14}{|l|}{ Dictyotales } \\
\hline \multicolumn{14}{|l|}{ Dictyotaceae } \\
\hline Canistrocarpus cervicornis (Kützing) De-Paula \& De Clerck & - & - & + & - & - & - & + & - & - & + & - & - & $\mathrm{F}$ \\
\hline Dictyopteris delicatula J.V.Lamour. & + & + & + & + & + & + & + & + & + & + & + & + & $\mathrm{F}$ \\
\hline Dictyopteris justii J.V.Lamour. & - & - & + & - & - & - & - & - & - & - & - & - & $\mathrm{F}$ \\
\hline Dictyota crenulata J. Agardh & - & - & - & - & - & - & - & + & - & + & + & - & $\mathrm{F}$ \\
\hline Lobophora variegata (J.V.Lamour.) Womersley ex E.C. Oliveira & - & - & - & - & - & + & - & - & + & - & - & + & $\mathrm{F}$ \\
\hline Padina boergesenii Allender \& Kraft & + & - & + & - & + & - & + & - & - & - & + & - & $\mathrm{F}$ \\
\hline Padina gymnospora (Kütz.) Sond. & + & + & + & - & + & + & + & + & + & + & + & + & $\mathrm{F}$ \\
\hline Spatoglossum schröederi (C. Agardh) Kütz. & + & - & + & + & + & + & - & + & - & - & - & + & $\mathrm{F}$ \\
\hline \multicolumn{14}{|l|}{ Fucales } \\
\hline \multicolumn{14}{|l|}{ Sargassaceae } \\
\hline Sargassum cymosum C.Agardh & + & + & + & + & + & + & + & - & + & + & - & + & $\mathrm{CR}$ \\
\hline \multicolumn{14}{|l|}{ Ectocarpales } \\
\hline \multicolumn{14}{|l|}{ Scytosiphonaceae } \\
\hline Colpomenia sinuosa (Roth) Derbès \& Solier & - & + & - & - & + & - & - & - & - & - & + & - & $\mathrm{FT}$ \\
\hline \multicolumn{14}{|l|}{ CHLOROPHYTA } \\
\hline Ulvales & & & & & & & & & & & & & \\
\hline Ulvaceae & & & & & & & & & & & & & \\
\hline Ulva fasciata Delile & + & + & + & + & + & + & + & + & + & + & + & + & $\mathrm{F}$ \\
\hline Ulva lactuca L. & + & + & + & + & + & + & + & + & + & + & + & + & $\mathrm{F}$ \\
\hline Uva rigida C. Agardh & - & - & - & - & - & - & + & + & + & + & + & + & $\mathrm{F}$ \\
\hline Ulva spp. & + & + & + & + & + & + & + & + & + & + & + & + & $\mathrm{F}$ \\
\hline Cladophorales & & & & & & & & & & & & & \\
\hline Anadyomenaceae & & & & & & & & & & & & & \\
\hline Anadyomene stellata (Wulfen in Jacq.) C. Agardh & - & - & + & - & + & + & - & - & - & + & - & + & $\mathrm{F}$ \\
\hline Cladophoraceae & & & & & & & & & & & & & \\
\hline Cladophora prolifera (Roth) Kütz. & - & - & - & + & - & - & - & - & - & - & + & - & FT \\
\hline Cladophora vagabunda (L.) C. Hoek & - & - & - & + & - & - & - & - & - & - & + & - & FT \\
\hline Siphonocladales & & & & & & & & & & & & & \\
\hline Siphonocladaceae & & & & & & & & & & & & & \\
\hline Dictyosphaeria verluysii Weber Bosse & - & - & - & - & - & - & - & + & - & + & + & - & FT \\
\hline Valoniaceae & & & & & & & & & & & & & \\
\hline Valonia aegagropila C. Agardh & - & - & - & + & - & - & + & + & - & - & + & - & FT \\
\hline Bryopsidales & & & & & & & & & & & & & \\
\hline Codiaceae & & & & & & & & & & & & & \\
\hline Codium intertextum Collins \& Herv. & - & + & - & - & - & - & - & - & - & - & - & + & FT \\
\hline Codium taylorii P.C. Silva & - & - & - & - & - & + & - & - & - & - & - & - & FT \\
\hline Caulerpaceae & & & & & & & & & & & & & \\
\hline Caulerpa cupressoides (H. West in Vahl) C. Agardh & - & - & - & - & - & + & - & - & + & + & - & - & $\mathrm{C}$ \\
\hline Caulerpa mexicana Sond. ex Kütz. & - & - & - & - & - & - & + & - & - & - & - & - & $\mathrm{F}$ \\
\hline Caulerpa racemosa (Forsskal) J.Agardh & - & - & + & - & - & - & - & - & - & - & - & + & FT \\
\hline Caulerpa sertularioides (S.G.Gmel.) M. Howe & - & - & - & - & - & - & + & - & - & + & - & + & $\mathrm{C}$ \\
\hline Halimedaceae & & & & & & & & & & & & & \\
\hline Halimeda cuneata K. Hering & - & - & + & - & + & + & - & - & + & - & - & - & A \\
\hline Halimeda discoidea Decne & - & - & - & - & - & - & - & - & - & - & - & + & A \\
\hline Halimeda gracilis Harv. Ex J. Agardh & - & - & + & - & - & - & + & + & + & + & - & + & A \\
\hline Halimeda incrassata (J.Ellis) J.V. Lamour. & - & - & - & - & - & - & - & - & - & + & + & - & A \\
\hline Halimeda opuntia (L.) J.V. Lamour. & - & - & - & - & - & - & + & - & - & - & - & - & $\mathrm{A}$ \\
\hline
\end{tabular}


Tabela 1. Continuação.

\begin{tabular}{|c|c|c|c|c|c|c|c|c|c|c|c|c|c|}
\hline \multirow{3}{*}{ TÁXONS } & \multicolumn{6}{|c|}{ Stella Maris } & \multicolumn{6}{|c|}{ Itacimirim } & \multirow{3}{*}{ Morfotipc } \\
\hline & \multicolumn{3}{|c|}{ Período Seco } & \multicolumn{3}{|c|}{ Período Chuvoso } & \multicolumn{3}{|c|}{ Período Seco } & \multicolumn{3}{|c|}{ Período Chuvoso } & \\
\hline & $\mathrm{PC}$ & RPR & RFR & PÇ & RPR & RFR & PÇ & $\mathrm{PR}$ & RFR & $\mathrm{PÇ}$ & $\mathrm{PR}$ & RFR & \\
\hline \multicolumn{14}{|l|}{ RHODOPHYTA } \\
\hline \multicolumn{14}{|l|}{ Corallinales } \\
\hline \multicolumn{14}{|l|}{ Corallinaceae } \\
\hline Jania capillacea Harv. & - & - & - & - & + & + & - & - & - & - & - & - & A \\
\hline Amphiroa anastomosans Weber Bosse & - & + & + & + & + & + & + & + & + & + & + & + & A \\
\hline Amphiroa fragilissima (L.) J.V.Lamour. & - & + & - & - & + & - & + & - & - & - & + & - & A \\
\hline \multicolumn{14}{|l|}{ Nemaliales } \\
\hline \multicolumn{14}{|l|}{ Galaxauraceae } \\
\hline Dichotomaria marginata (J.Ellis \& Sol.) Lamarck & - & - & - & + & - & - & - & - & - & - & - & + & $\mathrm{C}$ \\
\hline \multicolumn{14}{|l|}{ Ceramiales } \\
\hline Ceramiaceae & & & & & & & & & & & & & \\
\hline Centroceras clavulatum (C.Agardh in Kunth) Mont. in Durieu de Maisonneuve & - & - & - & + & - & + & - & - & - & - & + & - & FT \\
\hline Rhodomelaceae & & & & & & & & & & & & & \\
\hline Acanthophora muscoides (L.) Bory & + & + & + & + & + & + & - & + & + & + & + & + & $\mathrm{C}$ \\
\hline Acanthophora spicifera (Vahl) Borgensen & + & - & - & - & + & - & - & + & - & - & - & + & $\mathrm{C}$ \\
\hline Amansia multifida J.V.Lamour. & + & + & + & + & - & + & - & + & + & - & - & + & $\mathrm{C}$ \\
\hline Bryothamnion seaforthii (Turner) Kütz. & + & + & + & + & + & + & - & - & - & - & - & - & $\mathrm{C}$ \\
\hline Bryothamnion triquetrum (S.G.Gmel.) M. Howe & + & - & + & + & + & + & - & - & - & - & - & - & $\mathrm{C}$ \\
\hline Digenea simplex (Wulfen) C. Agardh & + & + & + & + & + & + & + & + & - & - & + & - & $\mathrm{C}$ \\
\hline Enantiocladia duperreyi (C. Agardh) Falkenb. In F. Schmitz & - & - & + & - & - & - & - & - & - & - & - & - & $\mathrm{C}$ \\
\hline Herposiphonia bipinnata M. Howe & - & - & - & - & - & + & - & - & - & - & - & - & FT \\
\hline Laurencia sp. & - & - & - & - & - & + & - & - & - & - & - & + & $\mathrm{C}$ \\
\hline Palisada perforata (Bory de Saint-Vincent) K.W. Nam & - & + & + & + & + & + & + & + & + & + & + & + & $\mathrm{C}$ \\
\hline Vidalia obtusiloba (C. Agardh) J. Agardh & + & - & + & - & + & + & - & - & - & - & - & - & $\mathrm{C}$ \\
\hline Spyridiaceae & & & & & & & & & & & & & \\
\hline Spyridia hypnoides (Bory in Belanger) Papenf. & - & - & + & - & + & + & - & - & - & - & - & - & FT \\
\hline Gelidiales & & & & & & & & & & & & & \\
\hline Gelidiaellaceae & & & & & & & & & & & & & \\
\hline Gelidiella acerosa (Forssk.) Feldmann \& Hamel & + & + & - & + & + & - & + & + & + & + & + & + & $\mathrm{C}$ \\
\hline Gigartinales & & & & & & & & & & & & & \\
\hline Cystocloniaceae & & & & & & & & & & & & & \\
\hline Hypnea musciformis (Wulfen in Jacquin) J.V. Lamour & + & + & + & + & + & + & + & + & + & + & + & + & $\mathrm{C}$ \\
\hline Gigartinaceae & & & & & & & & & & & & & \\
\hline Chondracantus acicularis (Roth) Fredericq & - & - & - & + & + & + & - & - & - & - & + & - & $\mathrm{C}$ \\
\hline Solieriaceae & & & & & & & & & & & & & \\
\hline Solieria filiformes (Kütz.) P.W. Gabrielson & + & - & + & - & + & - & - & - & - & - & - & - & $\mathrm{C}$ \\
\hline Gracilariales & & & & & & & & & & & & & \\
\hline Gracilariaceae & & & & & & & & & & & & & \\
\hline Gracilaria cervicornis (Turner) J. Agardh & - & - & - & - & - & - & - & - & + & - & - & - & $\mathrm{C}$ \\
\hline Gracilaria cuneata Aresch & - & - & + & - & - & - & - & - & - & - & - & - & $\mathrm{C}$ \\
\hline Gracilaria curtissae J. Agardh & - & - & - & - & - & - & - & - & - & - & - & + & $\mathrm{C}$ \\
\hline Gracilaria cylindrica Borgesen & - & - & + & - & - & + & - & - & - & - & - & - & $\mathrm{C}$ \\
\hline Gracilaria dominguensis (Kütz.) Sond. Ex Dickie & - & - & + & - & - & + & - & - & - & - & - & - & $\mathrm{C}$ \\
\hline Gracilaria sp. & - & - & - & - & - & + & - & - & - & - & - & - & $\mathrm{C}$ \\
\hline Hydropuntia caudata (J.Agardh) Gurgel \& Fredericq & - & - & + & - & - & - & - & - & - & - & - & - & $\mathrm{C}$ \\
\hline Hydropuntia cornea (J. Agardh) M. J. Wynne & - & - & - & - & + & - & - & - & - & - & - & - & $\mathrm{C}$ \\
\hline Halymeniales & & & & & & & & & & & & & \\
\hline Halymeniaceae & & & & & & & & & & & & & \\
\hline Cryptonemia seminervis (C. Agardh) J. Agardh & + & - & + & + & + & + & - & - & - & - & - & + & $\mathrm{C}$ \\
\hline Rhodymeniales & & & & & & & & & & & & & \\
\hline Lomentariaceae & & & & & & & & & & & & & \\
\hline Ceratodictyon variabile (Grev. ex J. Agardh) R.E. Norris & - & - & - & - & - & - & + & - & - & - & - & - & $\mathrm{C}$ \\
\hline TOTAL & 17 & 15 & 29 & 20 & 26 & 30 & 18 & 17 & 16 & 17 & 20 & 25 & \\
\hline
\end{tabular}




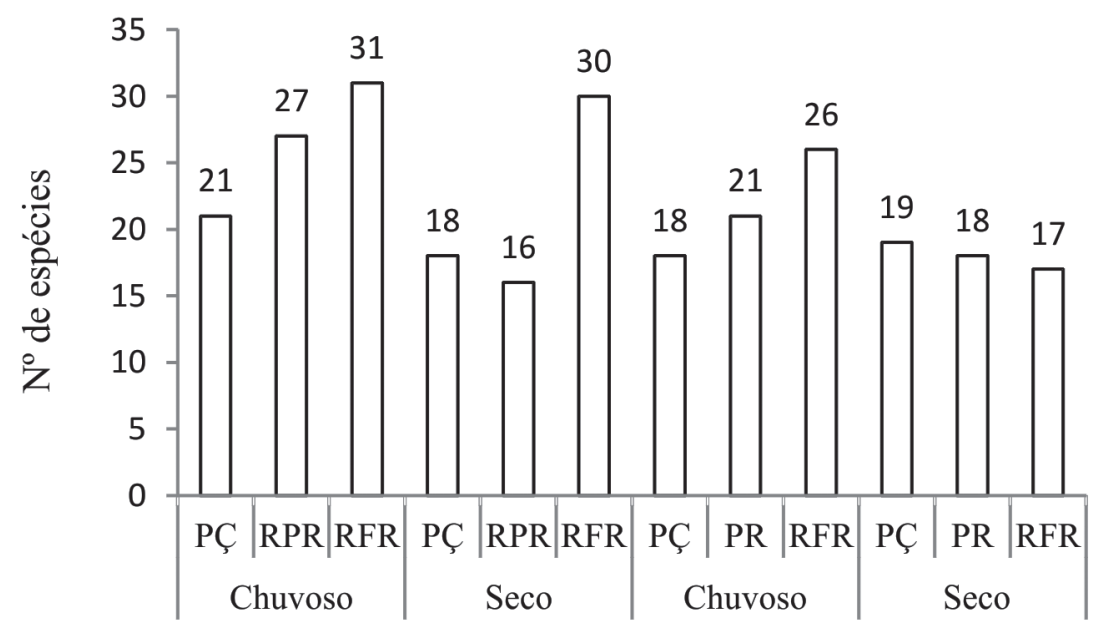

Stella Maris

Itacimirim

Figura 2. Representação gráfica do número total de espécies encontradas em cada período por ponto de coleta.

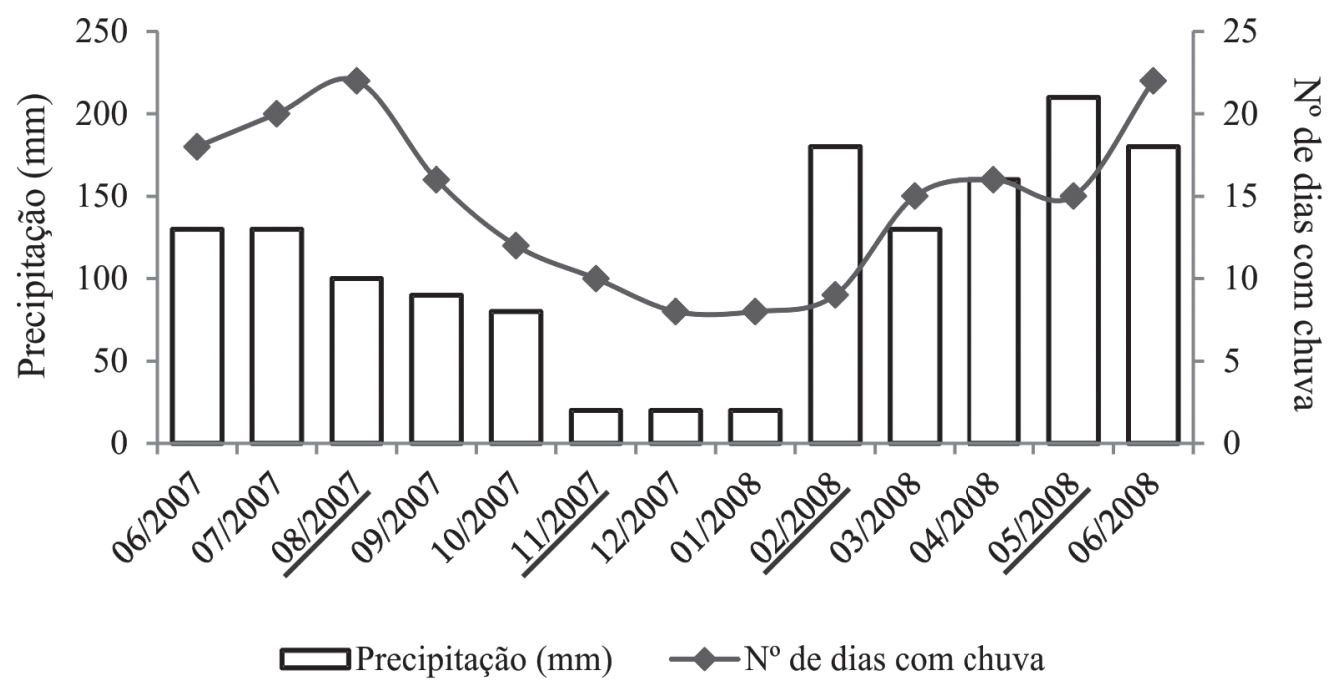

Figura 3. Representação gráfica de número de dias com chuva e chuva acumulada mensal para Região Metropolitana de Salvador para os períodos estudados, evidenciando os meses de amostragem. Fonte: INMET (www.inmet.gov.br).

pode limitar o desenvolvimento de certos grupos de algas, como observado por Barbosa et al. (2008). Entretanto, para que possamos afirmar a ocorrência de tais influências, faz-se necessário controle dos citados fatores através de medidas contínuas em estudos posteriores.

Considerando a biomassa por compartimento recifal, observou-se uma variação média total de $47 \pm 15 \mathrm{~g} \cdot \mathrm{m}^{-2}$ na PÇ em Itacimirim e $297 \pm 82$ g.m ${ }^{-2}$ na RFR de Stella Maris. A RFR de Stella Maris apresentou os valores mais elevados de biomassa, e estes foram significativamente diferentes (ANOVA, Tukey $\mathrm{p}<0,001$ ). Quando realizada a análise de similaridade, esta também revelou a diferença entre os microhabitats (ANOSIN, $\mathrm{r}=0,139 ; \mathrm{p}=0,001$ ), e no teste $a$ posteriori não foi encontrada diferença significativa entre as regiões de $\mathrm{PC}$ e as RPR, evidenciando que a diferença entre os compartimentos recifais é atribuída à RFR. A RFR apresentou tanto maior valor de biomassa quanto maior riqueza específica, isso se deve a características peculiares, já citadas, que este compartimento recifal possui, repetindo o mesmo padrão observado para o número de espécies.

O período chuvoso e seco, quando comparados em relação à biomassa, apresentou valores de $123 \pm 37$ e $105 \pm 48$ g. $\mathrm{m}^{-2}$, respectivamente, contudo não foi observada diferença significativa entre os períodos.

Com relação aos índices de diversidade (H') e equitabilidade (J') por compartimento recifal, não foram encontradas variações significativas entre os períodos, bem como, entre as praias estudadas ( $\mathrm{H}^{\prime}: \mathrm{p}=0,07 ; \mathrm{J}^{\prime}: \mathrm{p}=0,3$ ) (Fig. 7 e 8). Os 


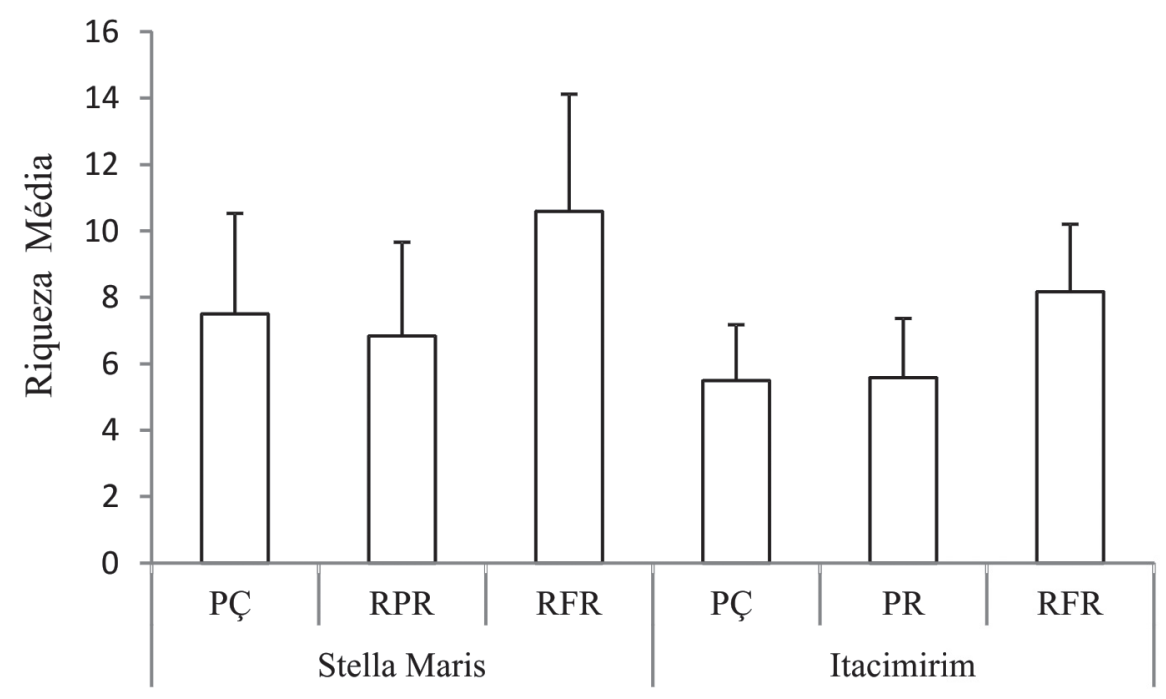

Figura 4. Representação gráfica da riqueza média encontrada nos compartimentos recifais, nas diferentes praias de estudo.

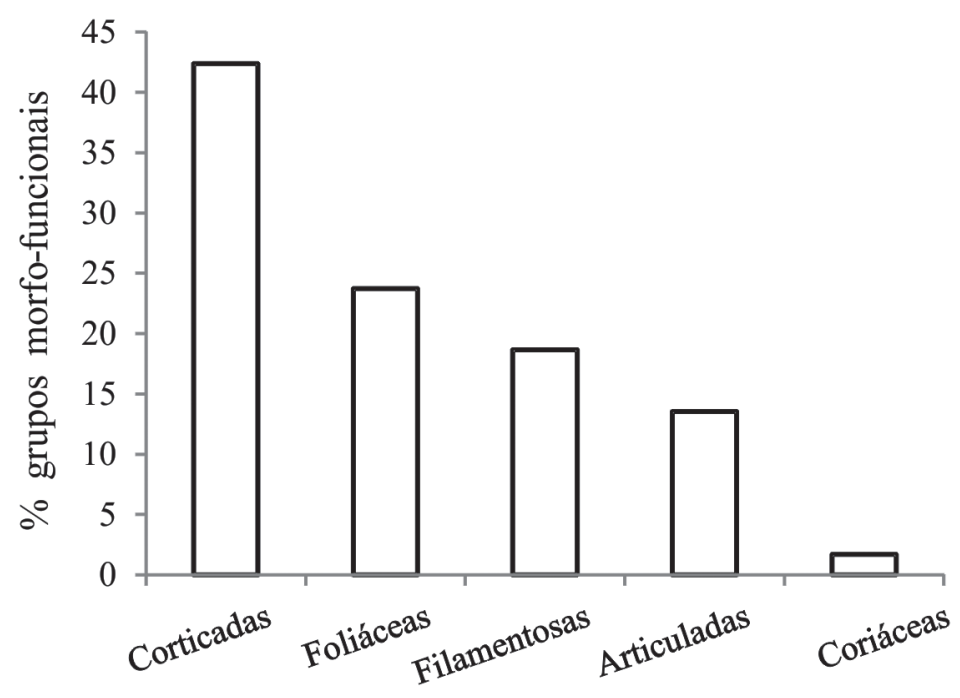

Figura 5. Representação gráfica da porcentagem de ocorrência dos grupos morfo-funcionais algais, nas duas praias estudadas.

índices mostram que houve equilíbrio entre os táxons, sem a predominância de um ou outro, como pode acontecer em locais com elevados níveis de perturbação, como aqueles influenciados por poluição orgânica. Os valores de H' e J' encontrados neste estudo podem ser considerados elevados, quando comparados a outros estudos que utilizaram tais índices, a exemplo de Barbosa et al. (2008 - mediolitoral), Marins et al. (2008 - infralitoral) e Ribeiro et al. (2008 infralitoral).

As rodofíceas, além de apresentarem o maior número de espécies, foram também as que contribuíram com maior valor de biomassa média nas praias estudadas, em Stella Maris obtiveram percentual de importância de 57\% e em Itacimirim de 70\% (Fig. 9). Resultado similar foi encon- trado por Muñoz \& Pereira (1997). Marins et al. (2008) observaram maior contribuição das ocrofíceas em relação às rodofíceas. Villaça (2002) observa que valores maiores de riqueza e biomassa em ocrofíceas podem indicar deterioração em ambientes recifais. Figueiredo et al. (2004) comentam que nas regiões tropicais as rodofíceas podem dominar o ambiente na ausência de algas pardas de grande porte, sugerindo assim, a existência de competição entre algas que ocupam diferentes estratos na comunidade.

Utilizando ANOVA foram observadas diferenças significativas nos valores de biomassa entre as espécies nas praias amostradas e entre os compartimentos recifais. E esta diferença demonstrou a melhor adaptação de algumas espécies a diferentes tipos de ambientes e graus de hidrodinamismo. 


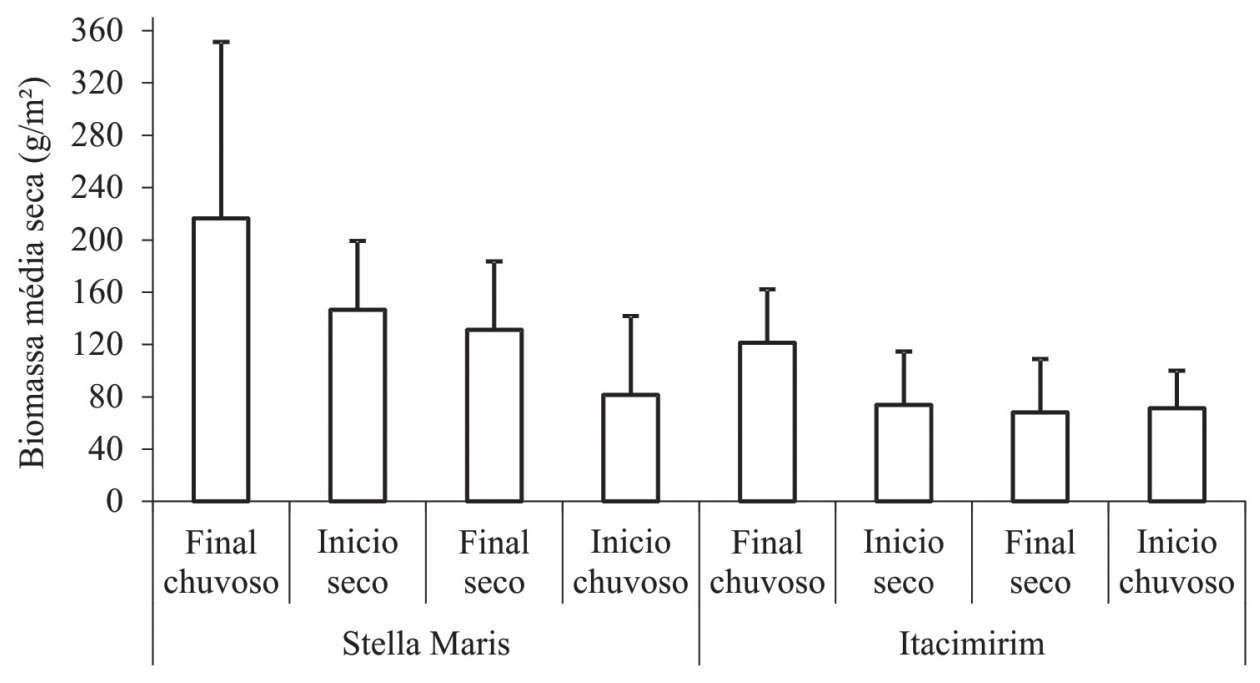

Figura 6. Representação gráfica da biomassa média total nos diferentes momentos de amostragem nas praias estudadas.

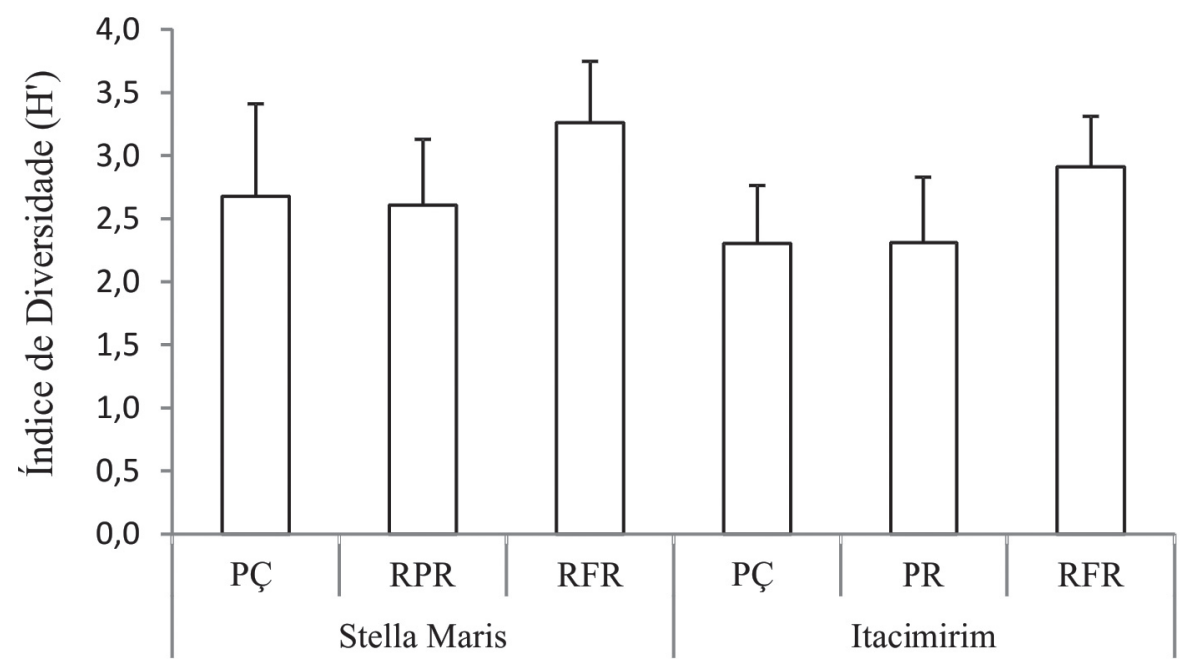

Figura 7. Representação gráfica dos índices de diversidade ( $\left.\mathrm{H}^{\prime}\right)$ encontrados para os microhabitats nas praias de estudo.

Quanto às praias, contribuíram com maior biomassa Acanthophora muscoides ( $\mathrm{p}<0,05)$, Amansia multifida $(\mathrm{p}<0,01)$, Cryptonemia seminervis $(\mathrm{p}<0,01)$, Gracilaria spp. $(\mathrm{p}<0,05)$, Padina boergesenii $(\mathrm{p}<0,05)$, Sargassum cymosum $(\mathrm{p}<0,001)$ e Ulva spp. $(\mathrm{p}<0,001)$ em Stella Maris em relação a Itacimirim (Tab. 2 e 3). A maior biomassa dos citados táxons em Stella Maris evidencia a adaptação destes ao forte grau de hidrodinamismo local, devido a morfologia recifal presente nesta praia. Assim, essas macroalgas estão sujeitas a ação das ondas, o que permite maior oxigenação da água e retirada de parte dos sedimentos que podem recobrir as algas (Barbosa et al. 2008). Mesmo as áreas que ficam totalmente descobertas durante a maré baixa são pulverizadas pelas ondas, propiciando sempre um aporte de água.
Gelidiella acerosa $(\mathrm{p}<0,001)$ e Palisada perforata $(\mathrm{p}<0,001)$ obtiveram maior valor de biomassa em Itacimirim quando comparada a Stella Maris. Essas algas possuem resistência à dessecação, devido ao seu morfotipo corticado, e tal adaptação é favorecida em ambientes como o de Itacimirim, onde existe um platô recifal que permanece totalmente emerso durante a maré baixa, e fica longos períodos expostos à incidência solar, o que resulta em intenso estresse e dessecação das macroalgas, além disso, em parte da sua extensão é recoberto por areia.

Bryothamnion triquetrum $(\mathrm{p}<0,001)$, Digenea simplex $(\mathrm{p}<0,05)$ e Vidalia obtusiloba $(\mathrm{p}<0,001)$ apresentaram variação significativa da biomassa entre os compartimentos recifais, com maiores valores na RFR. Neste compartimento 


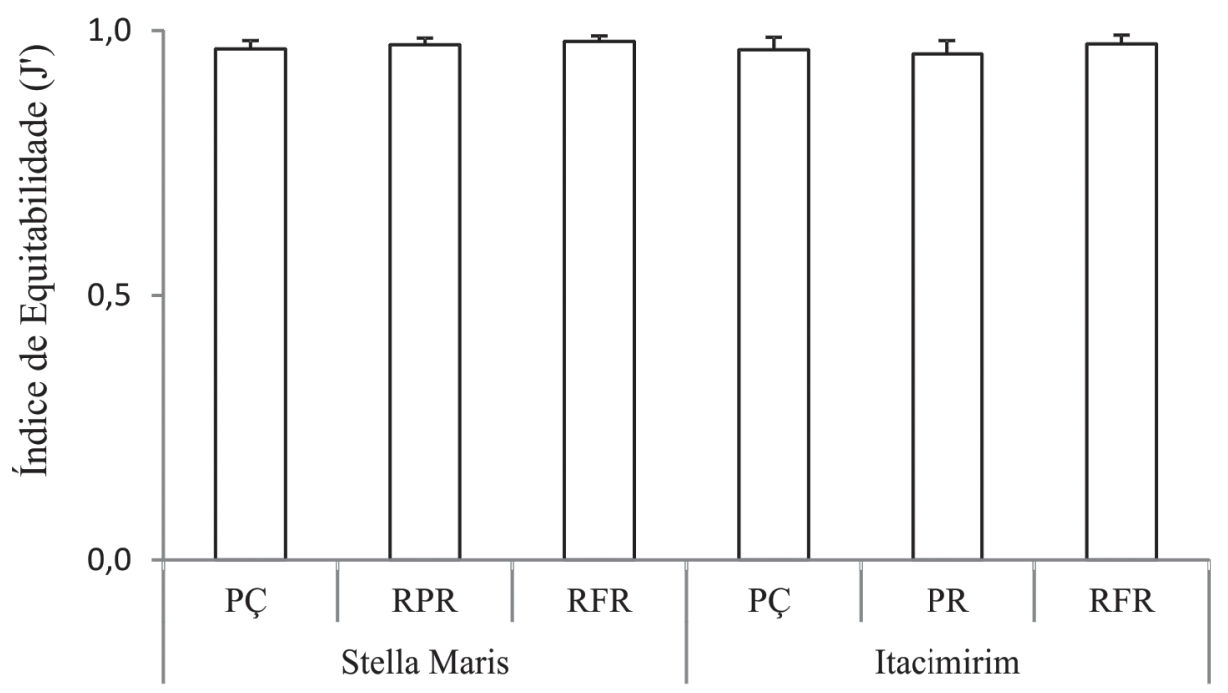

Figura 8. Representação gráfica dos índices de equitabilidade (J') encontrados para os microhabitats nas praias de estudo.

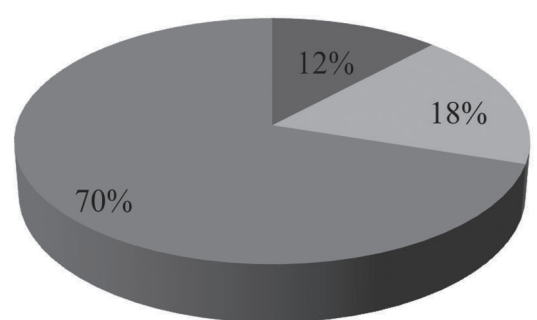

Itacimirim

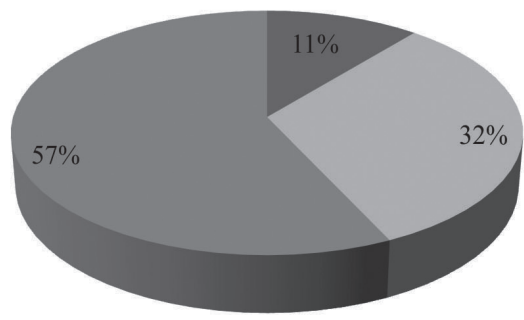

Stella Maris

Figuras 9. Representação gráfica do percentual de importância de biomassa dos grupos taxonômicos nas duas formações recifais estudadas.

recifal encontram-se as macroalgas de grande porte, que têm preferência por regiões de forte embate das ondas, ficando assim, menos tempo expostas durante a maré baixa. Para a biomassa das demais espécies encontradas, não foi detectada diferença significativa quando comparado as praias e os compartimentos recifais.

Os táxons que contribuíram com maiores valores de biomassa em ambas as praias foram Hypnea musciformis, Gelidiella acerosa, Sargassum cymosum, Palisada perforata, Ulva spp., Bryothamnion seaforthii e Padina gymnospora, fornecendo mais de $70 \%$ de toda biomassa encontrada.

Villaça et al. (2008) observaram que as algas pertencentes à grupos morfológicos mais complexos (corticadas e coralináceas articuladas) são melhor adaptadas a ambientes de maior hidrodinamismo e maior luminosidade, assim, ao longo de um gradiente vertical há uma substituição das algas com características mais rígidas por algas mais delicadas (foliáceas) em relação a áreas mais profunda. Villaça et al. (2010) comentam que regiões como platô recifal, são dominadas por tufos de macroalgas, a exemplo de Cladophora spp., Dictyopteris delicatula, Dictyosphaeria versluysii, Digenea simplex, Gelidiella acerosa e Halimeda opuntia. Taouil \& Yoneshigue-Valentin (2002) comentam que a abundância do gênero Gelidiella pode ser atribuída a ambientes moderadamente impactados, podendo este gênero junto com outros com mesmas características serem utilizados como bioindicadores em programas de despoluição.

Alguns estudos relatam a grande contribuição do gênero Sargassum, em termos de biomassa, para a composição de formações recifais, a exemplo de Costa Jr. et al. (2002) que destacam a predominância de Sargassum sp. e Padina gymnospora, juntamente com outras algas pardas no infralitoral de formações recifais no sul da Bahia. Marins et al. (2008) evidenciaram a predominância de Sargassum spp. na Baía de Todos os Santos.

Hypnea musciformis apresentou valores de biomassa superiores às demais espécies encontradas em Itacimirim. Em Stella Maris Sargassum cymosum contribuiu com os maiores valores de biomassa, seguido por $H$. musciformis. Reis et al. (2003) realizaram estudos para avaliar a relação 
Tabela 2. Biomassa $\left(\mathrm{g} \cdot \mathrm{m}^{-2}\right.$ ) e percentual de importância (Pi) dos táxons mais representativos na estrutura dos compartimentos recifais da praia de Stella Maris - BA.

\begin{tabular}{|c|c|c|c|c|c|c|c|c|c|c|c|c|}
\hline \multirow{2}{*}{ Stella Maris } & \multicolumn{6}{|c|}{ Período Seco } & \multicolumn{6}{|c|}{ Período Chuvoso } \\
\hline & $\mathrm{PCC}$ & & RPR & & RFR & & $\mathrm{PÇ}$ & & RPR & & RFR & \\
\hline Táxons & 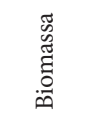 & $\stackrel{\circ}{\stackrel{2}{2}}$ & 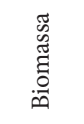 & $\stackrel{\circ}{\stackrel{2}{2}}$ & 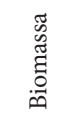 & $\stackrel{\partial}{\partial}$ & 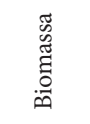 & $\stackrel{\circ}{\ddot{2}}$ & $\begin{array}{l}\tilde{B} \\
\tilde{0} \\
\tilde{\Xi} \\
\tilde{0} \\
.0\end{array}$ & 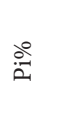 & 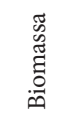 & 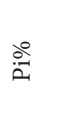 \\
\hline Sargassum cymosum & 21,2 & 16 & 48,3 & 33 & 40,4 & 19 & 4,6 & 4 & 14,3 & 8 & 22,9 & 12 \\
\hline Hypnea musciformis & 13,9 & 10 & 30,6 & 21 & 30,1 & 14 & 9,0 & 8 & 6,9 & 4 & 15,8 & 8 \\
\hline Gelidiella acerosa & 9,1 & 7 & 23,8 & 16 & 0,0 & 0 & 31,3 & 29 & 34,8 & 20 & 0,0 & 0 \\
\hline Bryothamnion seaforthii & 6,5 & 5 & 0,2 & 0 & 14,6 & 7 & 0,3 & 0 & 14,7 & 8 & 45,3 & 24 \\
\hline Ulva spp. & 18,6 & 14 & 16,5 & 11 & 17,0 & 8 & 2,7 & 2 & 11,0 & 6 & 12,2 & 6 \\
\hline Bryothamnion triquetrum & 8,4 & 6 & 0,0 & 0 & 22,3 & 11 & 3,9 & 4 & 3,4 & 2 & 19,6 & 10 \\
\hline Padina gymnospora & 10,1 & 7 & 0,0 & 0 & 0,0 & 0 & 8,5 & 8 & 18,6 & 10 & 16,9 & 9 \\
\hline Cryptonemia seminervis & 1,1 & 1 & 0,0 & 0 & 2,0 & 1 & 27,6 & 25 & 21,0 & 12 & 1,7 & 1 \\
\hline Amansia multifida & 10,6 & 8 & 1,8 & 1 & 20,4 & 10 & 0,4 & 0 & 0,0 & 0 & 3,4 & 2 \\
\hline Dictyopteris delicatula & 13,1 & 10 & 3,4 & 2 & 2,5 & 1 & 10,5 & 10 & 2,5 & 1 & 3,3 & 2 \\
\hline Osmundaria obtusiloba & 2,4 & 2 & 0,0 & 0 & 15,1 & 7 & 0,0 & 0 & 0,1 & 0 & 9,7 & 5 \\
\hline Gracilaria spp. & 1,2 & 1 & 0,0 & 0 & 8,1 & 4 & 1,0 & 1 & 3,6 & 2 & 8,7 & 5 \\
\hline Amphiroa fragilissima & 0,0 & 0 & 1,0 & 1 & 11,0 & 5 & 0,0 & 0 & 10,1 & 6 & 0,0 & 0 \\
\hline Padina boergesenii & 8,0 & 6 & 5,2 & 4 & 1,1 & 1 & 1,3 & 1 & 3,4 & 2 & 0,0 & 0 \\
\hline Palisada perforata & 0,0 & 0 & 1,3 & 1 & 0,4 & 0 & 1,5 & 1 & 7,9 & 4 & 5,3 & 3 \\
\hline Acanthophora muscoides & 4,8 & 4 & 3,6 & 2 & 3,9 & 2 & 0,1 & 0 & 1,7 & 1 & 2,1 & 1 \\
\hline Digenea simplex & 1,0 & 1 & 8,8 & 6 & 0,4 & 0 & 3,2 & 3 & 1,1 & 1 & 0,7 & 0 \\
\hline Jania capillacea & 0,0 & 0 & 0,0 & 0 & 0,0 & 0 & 0,0 & 0 & 6,6 & 4 & 7,8 & 4 \\
\hline Anadyomene stellata & 0,0 & 0 & 0,0 & 0 & 5,2 & 2 & 0,0 & 0 & 8,4 & 5 & 0,3 & 0 \\
\hline Spatoglossum schröederi & 3,0 & 2 & 0,0 & 0 & 0,2 & 0 & 0,2 & 0 & 1,8 & 1 & 6,4 & 3 \\
\hline
\end{tabular}

Tabela 3. Biomassa (g.m-2) e percentual de importância ( $\mathrm{Pi}$ ) dos táxons mais representativos na estrutura dos compartimentos recifais da praia de Itacimirim - BA.

\begin{tabular}{|c|c|c|c|c|c|c|c|c|c|c|c|c|}
\hline \multirow{2}{*}{ Itacimirim } & \multicolumn{6}{|c|}{ Período Seco } & \multicolumn{6}{|c|}{ Período Chuvoso } \\
\hline & $\mathrm{PÇ}$ & & PR & & RFR & & $\mathrm{PÇ}$ & & PR & & RFR & \\
\hline Táxons & 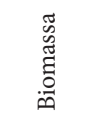 & $\stackrel{\ddot{2}}{\circ}$ & 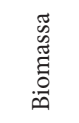 & $\stackrel{\partial}{\ddot{2}}$ & 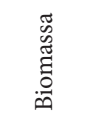 & $\stackrel{\ddot{\alpha}}{\circ}$ & 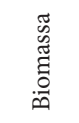 & $\stackrel{\partial}{\ddot{2}}$ & 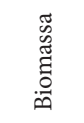 & $\stackrel{\circ}{\ddot{z}}$ & 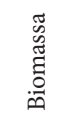 & $\stackrel{\circ}{\ddot{2}}$ \\
\hline Hypnea musciformis & 17,7 & 26 & 25,3 & 31 & 53,9 & 34 & 15,9 & 13 & 10,1 & 10 & 34,1 & 28 \\
\hline Gelidiella acerosa & 14,7 & 22 & 6,6 & 8 & 15,6 & 10 & 43,5 & 35 & 19,2 & 19 & 30,4 & 25 \\
\hline Palisada perforata & 11,7 & 17 & 19,6 & 24 & 10,2 & 6 & 39,4 & 32 & 35,4 & 35 & 11,6 & 9 \\
\hline Sargassum cymosum & 2,6 & 4 & 0,0 & 0 & 32,4 & 20 & 0,3 & 0 & 0,0 & 0 & 3,9 & 3 \\
\hline Ulva spp. & 1,5 & 2 & 3,1 & 4 & 2,4 & 1 & 14,5 & 12 & 5,4 & 5 & 2,7 & 2 \\
\hline Digenea simplex & 0,2 & 0 & 16,1 & 19 & 0,0 & 0 & 0,0 & 0 & 3,3 & 3 & 0,0 & 0 \\
\hline Padina gymnospora & 9,8 & 15 & 0,7 & 1 & 2,8 & 2 & 0,7 & 1 & 3,8 & 4 & 1,7 & 1 \\
\hline Dictyopteris delicatula & 0,8 & 1 & 0,8 & 1 & 4,7 & 3 & 0,5 & 0 & 0,5 & 0 & 10,1 & 8 \\
\hline Centroceras clavulatum & 0,0 & 0 & 0,0 & 0 & 0,0 & 0 & 0,0 & 0 & 16,8 & 16 & 0,0 & 0 \\
\hline Amphiroa fragilissima & 2,9 & 4 & 0,0 & 0 & 11,8 & 7 & 1,0 & 1 & 0,7 & 1 & 0,3 & 0 \\
\hline Gracilaria spp. & 0,0 & 0 & 0,1 & 0 & 9,4 & 6 & 0,2 & 0 & 0,0 & 0 & 4,5 & 4 \\
\hline Halimeda gracilis & 0,1 & 0 & 3,9 & 5 & 0,4 & 0 & 1,2 & 1 & 0,0 & 0 & 3,7 & 3 \\
\hline Gracilaria cervicornis & 0,0 & 0 & 0,0 & 0 & 7,6 & 5 & 0,0 & 0 & 0,0 & 0 & 0,0 & 0 \\
\hline Lobophora variegata & 0,0 & 0 & 0,0 & 0 & 1,5 & 1 & 0,0 & 0 & 0,0 & 0 & 6,2 & 5 \\
\hline Halimeda incrassata & 0,0 & 0 & 0,0 & 0 & 0,0 & 0 & 2,8 & 2 & 1,8 & 2 & 0,0 & 0 \\
\hline Acanthophora muscoides & 0,2 & 0 & 1,2 & 1 & 0,2 & 0 & 0,1 & 0 & 2,2 & 2 & 0,7 & 1 \\
\hline
\end{tabular}




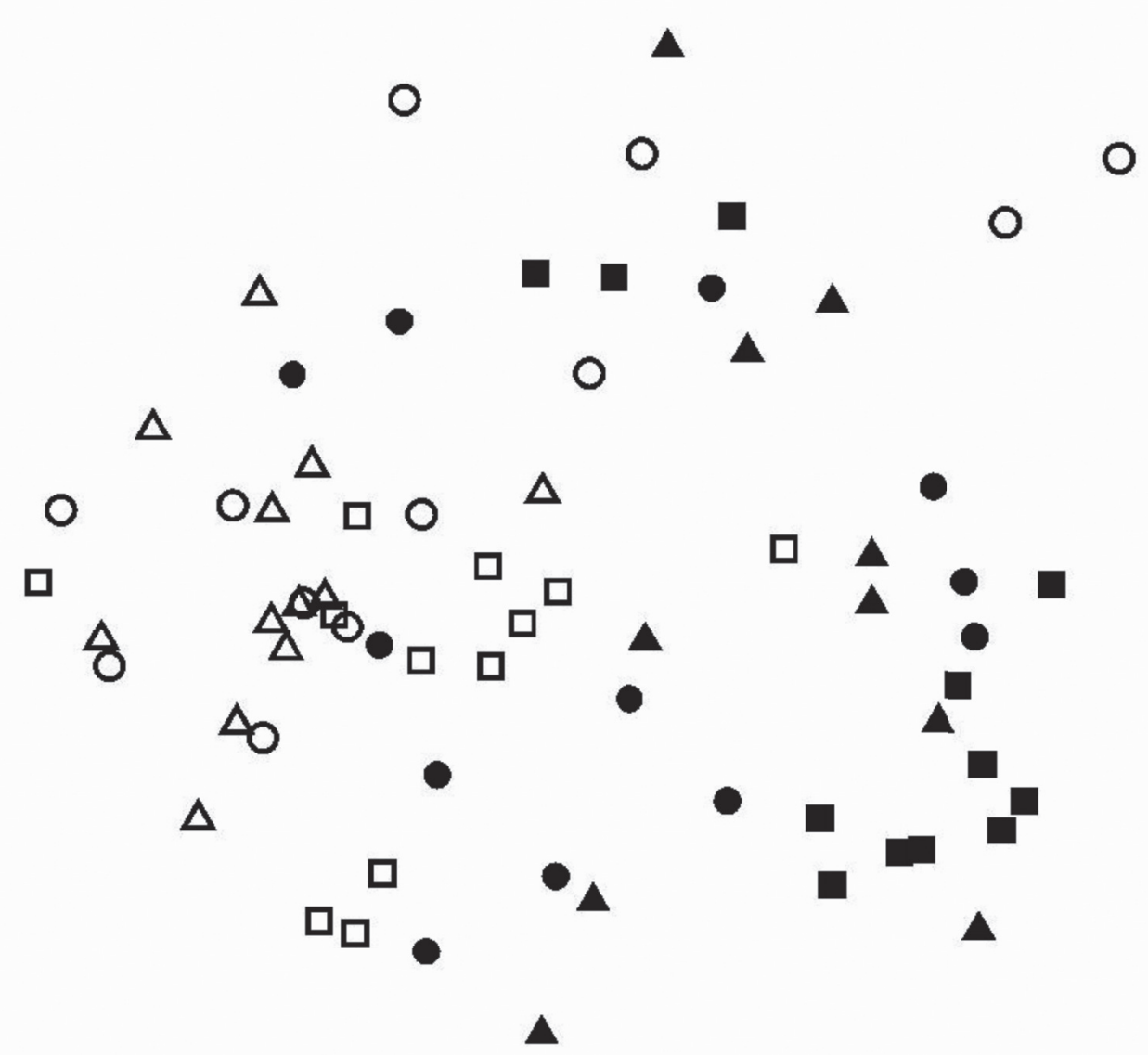

Figura 10. Análise do Escalonamento Multidimensional (MDS) dos dados da comunidade de algas associadas à população de Hypnea musciformis. $\triangle$ =Poça; $\bigcirc=$ Região protegida do recife; =Região frontal do recife. Ícones cheios representam Stella Maris e ícones vazios representam Itacimirim.

entre H. musciformis e S. cymosum, sendo este, considerado importante substrato para a fixação de $H$. musciformis e apontaram uma relação positiva entre os valores de biomassa de ambas. Nos estudos de Széchy \& Sá (2008) resultados similares foram encontrados, entretanto, variáveis não mostraram relação linear entre si, assim foi sugerido a influência de muitos fatores nessa interação. Reis (2009) comenta que em ambientes protegidos e moderados as algas corticadas são representadas principalmente por espécies de Hypnea, e em locais onde existem distúrbios físicos pode ocorrer dominância principalmente de espécies de Sargassum.

A partir da técnica de Escalonamento Multidimensional (MDS) foi possível observar que os elementos amostrais de uma mesma praia foram mais similares entre eles do que entre elementos de praias diferentes (Fig. 10). A Análise de Similiaridade (ANOSIM) indicou diferenças significativas entre as praias amostradas $(\mathrm{R}=0,493 ; \mathrm{p}=0,001)$, corroborando as observações do MDS. A diferença entre as comunidades das praias estudadas, provavelmente, pode ser atribuída à diferente fisionomia das formações recifais das praias. Enquanto a formação recifal de Stella Maris favoreceu a ocorrência de algas de maior porte e aspecto corticado, devido a suas irregularidades e heterogeneidade, a formação recifal de Itacimirim, por possuir um amplo platô recifal, que permanece totalmente descoberto durante as marés baixa, favoreceu a ocorrência de algas de menor porte, de ambientes arenosos e com maior resistência a dessecação.

\section{Agradecimentos}

Ao Programa Institucional de Bolsas de Iniciação Científica (PIBIC) pelo apoio financeiro.

\section{Referências}

Altamirano, M. \& Nunes, J.M.C. 1997. Contribuiciones al macrofitobentos del município de Camaçari (Bahia, Brasil). Acta Botanica Malacitana 22: 211-215.

Alves, A.M. 2008. Estudo morfo-taxonômico de Cladophorophyceae (Chlorophyta) do litoral do estado da Bahia, Brasil. Dissertação de Mestrado em Ciências - Botânica. Universidade Estadual de Feira de Santana, Feira de Santana.

Amado Filho, G.M.; Barreto, M.B.B.; Marins, B.V.; Felix, C. \& Reis, R.P. 2003. Estrutura das comunidades fitobentônicas do infralitoral da baía de Sepetiba, RJ, Brasil. Revista Brasileira de Botânica 26: 329-342.

Amado-Filho, G.M.; Horta, P.A.; Brasileiro, P.S.; Barros-Barreto, M.B. \& Fujii, M.T. 2006.Subtidal benthic marine algae of the marine state 
park of Laje de Santos (São Paulo, Brazil). Brazilian Journal of Oceanography 54: 225-234.

Amado-Filho, G.M.; Maneveldt, G.; Manso, R.C.C.; Marins-Rosa, B.V.; Pacheco, M.R. \& Guimarães, S.M.P.B. 2007. Estructura de los mantos de rodolitos de 4 a 55 metros de profundidad em la costa sur del estado de Espírito Santo, Brasil. Ciéncias Marinas 33: 1-12.

Amado-Filho, G.M.; Maneveldt, G.; Pereira-Filho, G.H.; Manso, R.C.C.; Bahia, R.G.; Barros-Barreto, M. B. \& Guimarães, S.M.P.B. 2010. Seaweed diversity associated with a Brazilian tropical rhodolith bed. Ciéncias Marinas 36: 371-391.

Bahia, R.G.; Abrantes, D.P.; Brasileiro, P.S.; Pereira-Filho, G.H. \& AmadoFilho, G.M. 2010. Rhodolith bed structure along a depth gradient on the northern coast of Bahia state, Brazil. Brazilian Journal of Oceanography 58: 323-337.

Barata, D. 2004. Clorofíceas marinhas bentônicas do Estado do Espírito Santo. Dissertação de Mestrado em Ciências Biológicas. Instituto de Botânica da Secretaria de Estado do Meio Ambiente, São Paulo.

Barata, D. 2008. Taxonomia e Filogenia do Gênero Caulerpa J.V. Lamour. (Bryopsidales, Chlorophyta) no Brasil. Tese de Doutorado em Biodiversidade Vegetal e Meio Ambiente. Instituto de Botânica da Secretaria de Estado do Meio Ambiente, São Paulo.

Barbosa, S.O.; Figueiredo, M.A.O. \& Testa, V. 2008. Estrutura e dinâmica de comunidades bentônicas dominadas por macrófitas na zona intramareal da praia de Jacaraípe, Espírito Santo, Brasil. Hoehnea 35: $563-575$

Bouzon, Z.L. 2006. Histoquímica e ultra-estrutura da ontogênese dos tretrasporângios de Hypnea musciformis (Wulfen) J. V. Lamour. (Gigartinales, Rhodophyta). Revista Brasileira de Botânica 29: 229-238.

Concentino, A.L.M.; Fujii, M.T.; Reis, N.V.; Guimarães-Barros, N.C.; Rocha, M.F. \& Neumann-Leitão, S. 2010. Diversity and distribution Patterns of the infralitoral green macroalgae from Potiguar basin, Rio Grande do Norte, Northeastern Brazil. Acta Botanica Brasilica 24: 986-996.

Costa Jr., O.S.; Atrill, M.J.; Pedrini, A.G. \& De-Paula, J.C. 2002. Spatial and seasonal distribution of seaweeds on coral reefs from Southern Bahia, Brazil. Botanica Marina 45: 346-355.

Figueiredo, M.A.O.; Barreto, M.B.B. \& Reis, R.P. 2004. Caracterização das macroalgas nas comunidades marinhas da Área de proteção Ambiental de Cairuçú, Parati, RJ - subsídios para futuros monitoramentos. Revista Brasileira de Botânica 27: 11-17.

Fujii, M.T.; Barata, D.; Chiracava, S. \& Guimarães, S.M.P.B. 2008. Cenário brasileiro da diversidade de algas marinhas bentônicas e sua contribuição para a política de conservação dos recursos naturais e do meio ambiente. Pp. 375-377. In: 59 Congresso Nacional de Botânica, 2008, Natal. Atualidades, Desafios e Perspectivas da Botânica no Brasil. Natal. Imagem Gráfica e Editora Ltda.

Horta, P.A.; Amâncio, E.; Coimbra, C.S. \& Oliveira, E.C. 2001. Considerações sobre a distribuição e origem da flora de macroalgas marinha brasileiras. Hoehnea 28: 243-265.

Laborel, J.L. 1967. A revised listo f Brazilian scleratinion corals and description of a new species. Bulletin of the Peabody Museum of Natural History 107: 14.

Littler, D.S. \& Littler, M.M. 2000. Caribbean reef plants. An identification guide to the reef plants of the Caribbean, Bahamas, Florida and Gulf of Mexico. Washington, Off Shore Graphics,.

Lobban, C.S. \& Harrison, P.J. 1994. Seaweed Ecology and Physiology. Cambridge, Cambridge University Press.

Lucio, A.M. \& Nunes, J.M.C. 2002. Aporación al conocimiento fenológico de las rodofíceas marinas de la playa de Guarajuba (Camaçari, Bahia) Brasil. Botanica Complutensis 26: 17-34.

Lyra, G.M. 2005. Distribuição, abundância e fenología de sete espécies simpátricas de Gracilaria na praia de Stella Maris, Salvador, Bahia. Dissertação de Mestrado em Ecologia e Biomonitoramento. Instituto de Biologia da Universidade Federal da Bahia. Salvador.

Lyra, G.M.; Santos, A.C.C. \& Nunes, J.M.C. 2007. Rodofíceas bentônicas das praias da Concha e Engenhoca, Município de Itacaré - Bahia, Brasil. Acta Botanica Malacitana 32: 234-240.

Marins, B.V., Brasileiro, P.A., Barreto, M.B.B., Nunes, J.M.C., YoneshigueValentin, Y.; Amado Filho, G.M. 2008. Subtidal bentic marine algae of the Todos os Santos Bay, Bahia state, Brazil. Oecologia Brasiliensis 12: $229-242$.

Mansilla, A. \& Pereira, S. 2001. Comunidades y diversidad de macroalgas em pozas intermareales de arrecifes. Pp. 315-330. In: Alveal, K. \& Antezana, T. (Eds.). Sustentabilidadde la biodiversidad, um problema actual. Bases cientifico-técnicas, teorizaciones y proyecciones. Concepción, Universidad de Concepción.

Martins, D.V., Cordeiro-Marino, M., Boccanera, N.B. \& Nunes, J.M.C. 1991. Clorofíceas marinhas bentônicas do município de Salvador, Bahia. Hoehnea 18: 115-133.

Moura, C. W. N. 2000. Coralináceas com genículo (Rhodophyta, Corallinales) do litoral do Brasil. Tese de Doutorado em Ciências. Instituto de Biociências da Universidade de São Paulo, São Paulo.

Muñoz, A.O.M. \& Pereira, S.M.B. 1997. Caracterização quali-quantitativa das comunidades de macroalgas nas formações recifais da praia do Cupe - Pernambuco, Brasil. Trabalho do Instituto Oceanográfico da Univiversidade Fedederal do Pernambuco 25: 93-109.

Nolasco, M.C. 1988. Construções carbonáticas da costa nordeste do estado da Bahia. Dissertação de Mestrado em Geologia. Instituto de Geociências da Universidade Federal da Bahia. Salvador.

Nunes, J.M. de C. 1997. Hypneaceae, Rhodymeniaceae, Ceramiaceae e Rhodomelaceae das praias e Placafor e Itapuã, município de Salvador, Bahia, Brasil. Biotemas 10: 61-75.

Nunes, J.M. de C. 1998a. Rodofíceas marinhas bentônicas da orla oceânica de Salvador, estado da Bahia, Brasil. Insula 49: 27-37.

Nunes, J.M. de C. 1998b. Catálogo de algas marinhas bentônicas do estado da Bahia. Acta Botanica Malacitana 23: 5-21.

Nunes, J.M. de C. 1999. Phaeophyta da região metropolitana de Salvador, Bahia, Brasil. Dissertação de Mestrado em Biologia. Instituto de Biologia da Universidade de São Paulo, São Paulo.

Nunes, J.M. de C.; Santos, A.C.C.; Minervino, A. \& Brito, K. S. 1999. Algas marinhas bentônicas do município de Ilhéus, Bahia, Brasil. Acta Botanica Malacitana 24: 5-12.

Nunes, J.M. de C.; Santos, A.C.C.; Minervino, A. \& Brito, K.S. 2001. Marine benthic algae from Uruçuca, Bahia, Brazil. Acta Botanica Malacitana 26: 181-187.

Nunes, J. M. de C. \& Paula, E. J de. 2002. Composição e distribuição das Phaeophyta nos recifes da região metropolitana de Salvador, Bahia, Brasil. Iheringia, Série Botânica 57: 113-130.

Nunes, J.M. de C. \& Paula, E.J de. 2004a. Chnoosporaceae, Scytosipnoneaceae, Sporochnaceae e Sphacelariaceae (Phaeophyta) no estado da Bahia, Brasil. Biotemas 17: 7-28.

Nunes, J.M. de C. \& Paula, E.J de. 2004b. Estudos taxonômicos de Ectocarpaceae e Ralfsiaceae (Phaeophyta) da região metropolitana de Salvador, Bahia, Brasil. Acta Biologica Leopoldensia 26: 37-50.

Nunes, J.M. de C. 2005a. Rodofíceas marinhas bentônicas do estado da Bahia, Brasil. Tese de Doutorado em Ciências. Universidade de São Paulo, São Paulo.

Nunes, J.M. de C. 2005b. A família Liagoraceae (Rhodophyta, Nemaliales) no estado da Bahia, Brasil. Hoehnea 32: 429-444.

Nunes, J.M. de C.; Santos, A.C.C. \& Santana, L.C. 2005. Novas ocorrências de algas marinhas bentônicas para o estado da Bahia, Brasil. Iheringia 60: $99-106$

Nunes, J.M. de C. \& Paula, E.J de. 2006. O gênero Dictyopteris J. V. Lamour. (Dictyotaceae - Phaeophyta) no estado da Bahia - Brasil. Hidrobiológica 16: 251-258.

Nunes, J.M. de C. \& Guimarães, S.M.P.B.; Donnangelo, A.; Farias, J. 2008. Aspectos taxonômicos de três espécies de coralináceas não geniculadas do litoral do estado da Bahia, Brasil. Rodriguésia 59: 75-86.

Nunes, J.M. de C. \& Guimarães, S.M.P.B. 2008. Novas referências de rodofíceas marinhas bentônicas para o litoral brasileiro. Biota Neotropica 8: 89-100.

Nunes, J.M. de C. \& Guimarães, S.M.P.B. 2009. Primeira referência de plantas gametofíticas em Spermothamnion nonatoi (Ceramiales, Rhodophyta). Rodriguésia 60: 259-264.

Nunes, J.M. de C. 2010. Taxonomia morfológica: metodologia de trabalho. Pp. 53-70. In: Pedrini, A.G. (Org.). Macroalgas - Uma introdução à taxonomia. Série Flora Marinha do Brasil. vol. 1. Rio de Janeiro, Technical Books Editora. 
Nunes, J.M. de C. \& Guimarães, S.M.P.B. 2010. Morfología y toxonomía de Scinaia halliae (Scinaiaceae, Rhodophyta) em El litoral de Bahia y Espírito Santo, Brasil. Revista de Biología Marina y Oceonografía 45: $159-164$.

Oigman-Pszczol, S.S.; Figueiredo, M.A.O. \& Creed, J.C. 2004. Distribution of Benthic Communities on the Tropical Rocky Subtidal of Armação dos Búzios, Southeastern Brazil. Marine Ecology 25: 173-190.

Oliveira, E.C. 2002. Macroalgas marinhas da costa brasileira - Estado do conhecimento, usos e conservação biológica. Pp. 122-126. In: Araújo, E.L.; Moura, A.N.; Sampaio, E.V.S.B.; Gestinari, L.M.S. \& Carneiro, J.M.T. Biodiversidade, conservação e uso sustentável da flora do Brasil. Recife, UFPE,

Oliveira-Carvalho, M.F.; Pereira, S.M.B. \& Zickel, C.S. 2003. Florística e distribuição espaço-temporal das clorofíceas bentônicas em trechos recifais do litoral norte do estado de Pernambuco - Brasil. Hoehnea 30: 201-212.

Oliveira-Filho, E.C. de. 1977. Algas Marinhas Bentônicas do Brasil. Tese (Livre - Docência em Ficologia) - Instituto de Biociências, Universidade de São Paulo. São Paulo.

Pereira, S.M.B. 2002. Desenvolvimento e situação atual do conhecimento das macroalgas marinhas das regiões Nordeste e Norte. Pp. 117-121. In: Araújo, E.L.; Moura, A.N.; Sampaio, E.V.S.B.; Gestinari, L.M.S. \& Carneiro, J.M.T. Biodiversidade, conservação e uso sustentável da flora do Brasil. Recife, UFPE.

Reis, R.P. \& Yoneshigue-Valentin, Y. 1998. Variação espaço-temporal de populações de Hypnea musciformis (Rhodophyta, Gigartinales) na baía de Sepetiba e armações dos Búzios, RJ, Brasil. Acta Botanica Brasilica 12: 465-483.

Reis, R.P. 2009. Caracterização as assembléia fitobentônica da praia do Kutuca, ilha da Marambaia, baía de Sepetiba, RJ, Brasil. Acta Botanica Brasilica 23: 297-304.

Ribeiro, F.A.; Travassos Jr., A.; Gestinari, L.M.; Torres, J.; Lima, K.K.A.; Santos, M.D.; Lira, G.A.S.T.; Fontes, K.A.A.; Pereira, S.M.B. \& Yoneshigue-Valentin, Y. 2008. Análise quali-quantitativa das populações algáceas de um trecho recifal a praia de Boa Viagem, PE. Oecologia Brasiliensis 12: 222-228.

Riul, P.; Laccouth, P.; Pagliosa, P.R.; Christoffersen, M.L. \& Horta, P.A. 2009. Rhodolith beds at the easternmost extreme of South America: Community structure of an endangered environment. Aquatic Botany 90: 315-320.

Steneck, R.S. \& Dethier, M.N. 1994. A functional group approach to the structure of algal - dominated communities. Oikos 69: 476-498.

Széchy, M.T.M. \& Sá, A.D.F. 2008. Variação sazonal do epifitismo por macroalgas em uma população de Sargassum vulgare C. Agardh (Phaeophyceae, Fucales) da baía da Ilha Grande, Rio de Janeiro. Oecologia Brasiliensis 12: 299-314.

Taouil, A. \& Yoneshigue-Valentin, Y. 2002. Alterações na composição florística das algas da praia de Boa Viagem (Niterói, RJ). Revista Brasileira de Botânica 25: 405-412.

Villaça, R. \& Pitombo, F.B. 1997. Benthic communities of shallow-water reefs of Abrolhos, Brazil. Revista Brasileira de Oceanografia 45: 35-43.

Villaça, R. 2002. Recifes biológicos. Pp. 229-248. In: Pereira, R.C.\& SoaresGomes, A. (Orgs.). Biologia marinha. Rio de Janeiro, Interciência.

Villaça, R.; Yoneshigue-Valentin, Y. \& Boudouresque, C.F. 2008. Estrutura da comunidade de macroalgas do infralitoral do lado exposto da ilha de Cabo Frio (Arraial do Cabo, RJ). Oecologia Brasiliensis 12: 206-221.

Villaça, R.; Fonseca, A.C.; Jensen, V.K. \& Knoppers, B. 2010. Species composition and distribution of macroalgae on Atol das Rocas, Brazil, SW Atlantic. Botanica Marina 53: 113-122.

Wynne, M.J. 2011. A checklist of the benthic marine algae of the tropical and subtropical Western Atlantic: third revision. Nova Hedwigia 140: $1-160$.

Yoneshigue-Valentin, Y.; Gestinari, L.M.S. \& Fernandes, D.R.P. 2006. Capítulo 2. Macroalgas. Pp. 67-105. In: Lavrado, H.P. \& Ignácio, B.L. (Eds.). Biodiversidade bentônica da região central da Zona Econômica Exclusiva brasileira. Rio de Janeiro, Museu Nacional. (Série Livros 18).

Zar, J.H. 1996. Biostatistical analysis. New Jersey, Prentice-Hall. 